\title{
Protection of the Reconstructed Nipple by Using a Breathing Bag Connection Tube
}

\section{Hyun Gyo Jeong ${ }^{1}$, \\ Jung-Kook Song', \\ Byung Min Yun ${ }^{3}$}

${ }^{1}$ Jeong Hyun Gyo Aesthetic Plastic Clinic, Seoul; Departments of ${ }^{2}$ Preventive

Medicine, ${ }^{3}$ Plastic \& Reconstructive

Surgery, College of Medicine, Jeju

National University, Jeju, Korea

No potential conflict of interest relevant to this article was reported.

\begin{abstract}
As the newly reconstructed nipple tends to be flattened, especially if submitted to pressure, prudent dressings using various protective devices as a physical support against pressure on a new nipple is important. We used a breathing bag connecting tube as a protective device in nipple reconstruction. A breathing bag connecting tube recycled was cut and trimmed at $1 \mathrm{~cm}$ above the height of the reconstructed nipple. Before stitch out, the newly reconstructed nipple with a local flap was dressed and protected in this way for 10 days after surgery. After stitch out, patients learnt how to manage the new nipple at home. The sole means of nipple dressing was affixing the breathing bag connecting tube with adhesive tape. Two patients had worn the tube for two months with the best compliance. Owing to the soft composition of the tube material, it is possible for a surgeon to have an easy cutting and trimming of the tube at appropriate heights as well as for a patient to show better compliance yielding better results. The cost factor is another advantage.
\end{abstract}

Keywords Nipple reconstruction, Protective device, Breathing bag, Nipple dressing

\section{INTRODUCTION}

Nowadays, local flap coverage methods, including the C-V breast flap compose the majority of nipple reconstruction procedures [1]. As the projection of new nipple from the $\mathrm{C}-\mathrm{V}$ breast flap is basically subcutaneous fat, the reconstructed nipple tends to be flattened over the long term, especially if submitted to pressure. In addition, necrosis or abrasion may result in flap failure. For this reason, it has been a principle to overcorrect the nipple height and to provide prudent dressings using various protective devices as a physical support against pressure on the reconstructed nipple [1].

The authors propose the use of a breathing bag connecting tube

Received: Aug 28, 2013 Revised: Oct 2, 2013 Accepted: Oct 18, 2013 Correspondence: Byung Min Yun Department of Plastic \& Reconstructive Surgery, College of Medicine, Jeju National University, 66 Jejudaehak-ro, Jeju 690-756, Korea. E-mail: almostfree@hanmail.net

http://submit.e-aaps.org/

Copyright (๑) 2013 The Korean Society for Aesthetic Plastic Surgery.

This is an Open Access article distributed under the terms of the Creative Commons Attribution Non-Commercial License (http://creativecommons.org/licenses/by-nc/3.0/) which permits unrestricted non-commercial use, distribution, and reproduction in any medium, provided the original work is properly cited as a protective device in nipple reconstruction.

\section{IDEA INNOVATION}

\section{Methods}

Material required was the breathing bag connecting tube commonly used in general anesthesia. It cannot but be acquired from the breathing bag following operation. Even though its types may vary according to the producing company, the basic structure is all the same, making any type appropriate (Fig.1). After having been washed in alcohol or betadine and dried, a breathing bag connecting tube was cut and trimmed at $1 \mathrm{~cm}$ above the height of the reconstructed nipple (Fig. 2). The reconstructed nipple with a local flap needs a prudent dressing until the time of stitch out (Fig. 3). Firstly, the suture area of the wound was given the compression dressing using Steri-strip ${ }^{\circledR}$ (3M healthcare, St. Paul, MN, USA) to avoid a hematoma below the flap. Secondly, the impregnated gauze covering was wide enough to stabilize the flap. Thirdly, the new nipple was offered a valid protection against pressure by the breathing bag connecting tube and is applied ample ointment to keep moisture (Fig. 4). And lastly, the wound dressing was completed with paper tape and gauze of appropriate size (Fig. 5). The 


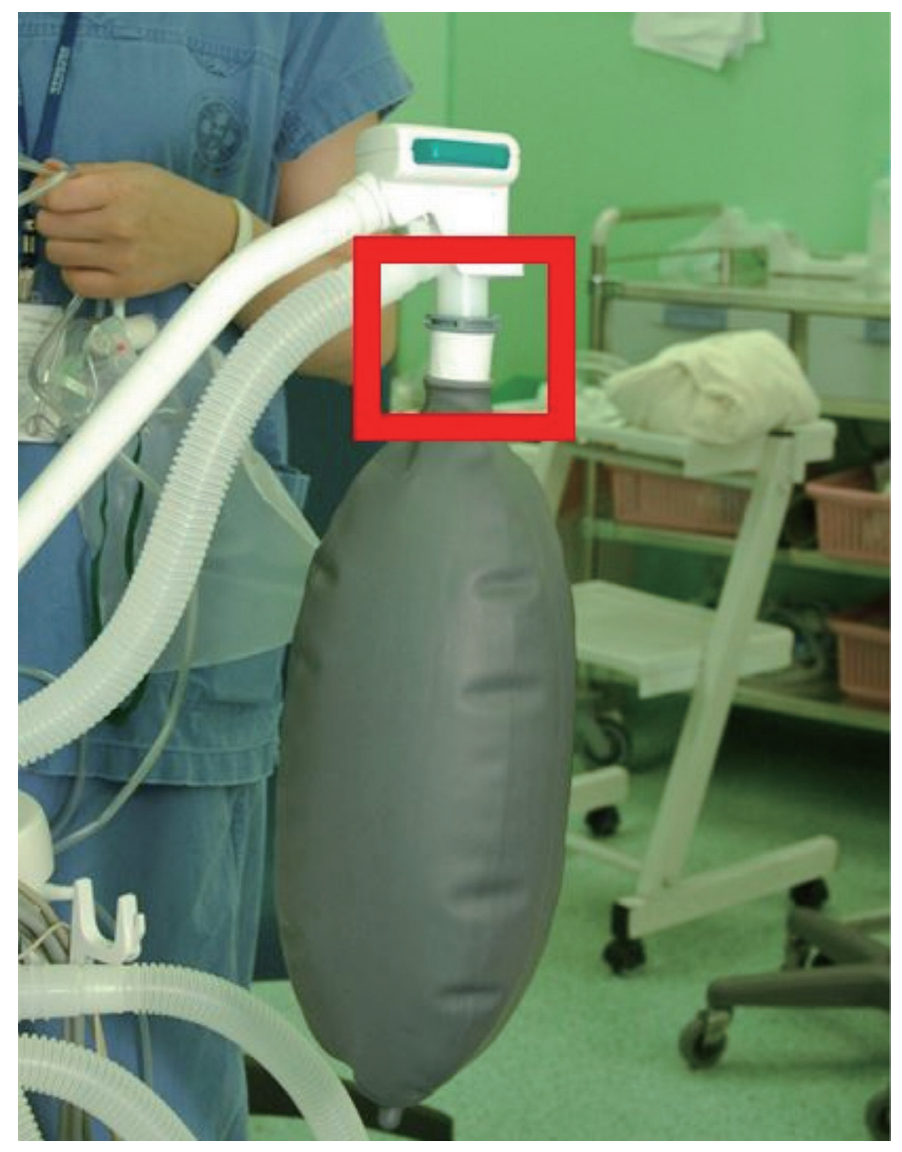

Fig. 1. Image of the connecting tube of the breathing bag for general anesthesia.

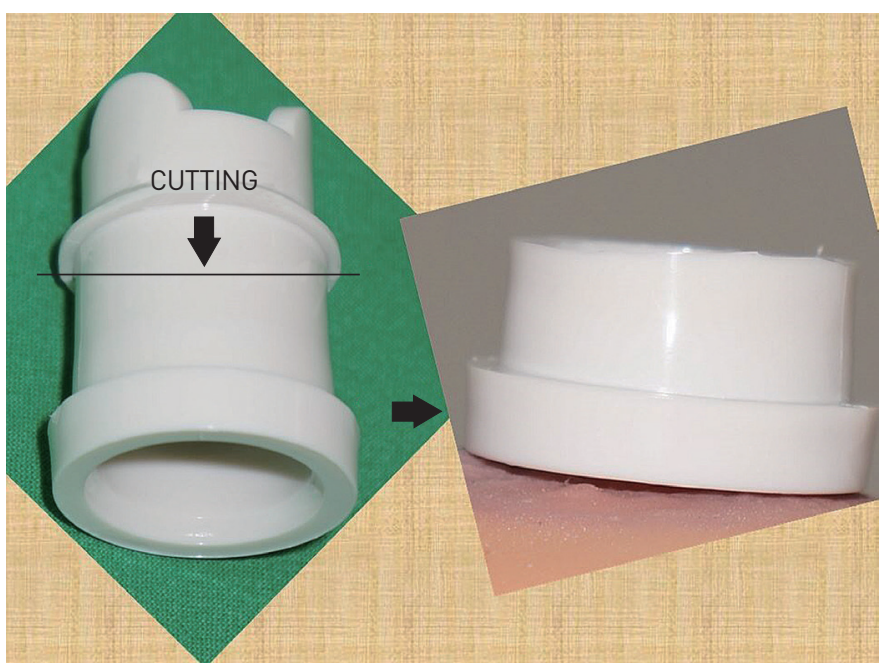

Fig. 2. The soft composition of a tube material ensures an easy cutting and trimming.

instruction how to manage the new nipple at home was given to the patient at the time of stitch out in 10 days. The breathing bag connecting tube could be simply affixed with adhesive tape (Fig.

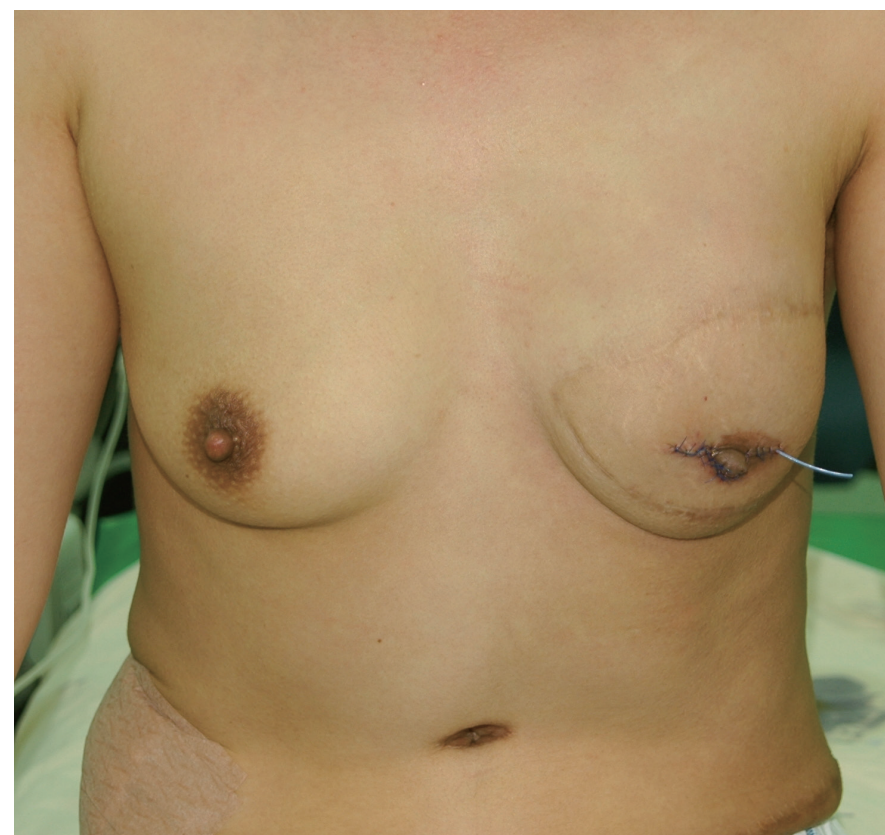

Fig. 3. Image of the reconstructed nipple with a modified C-V flap.

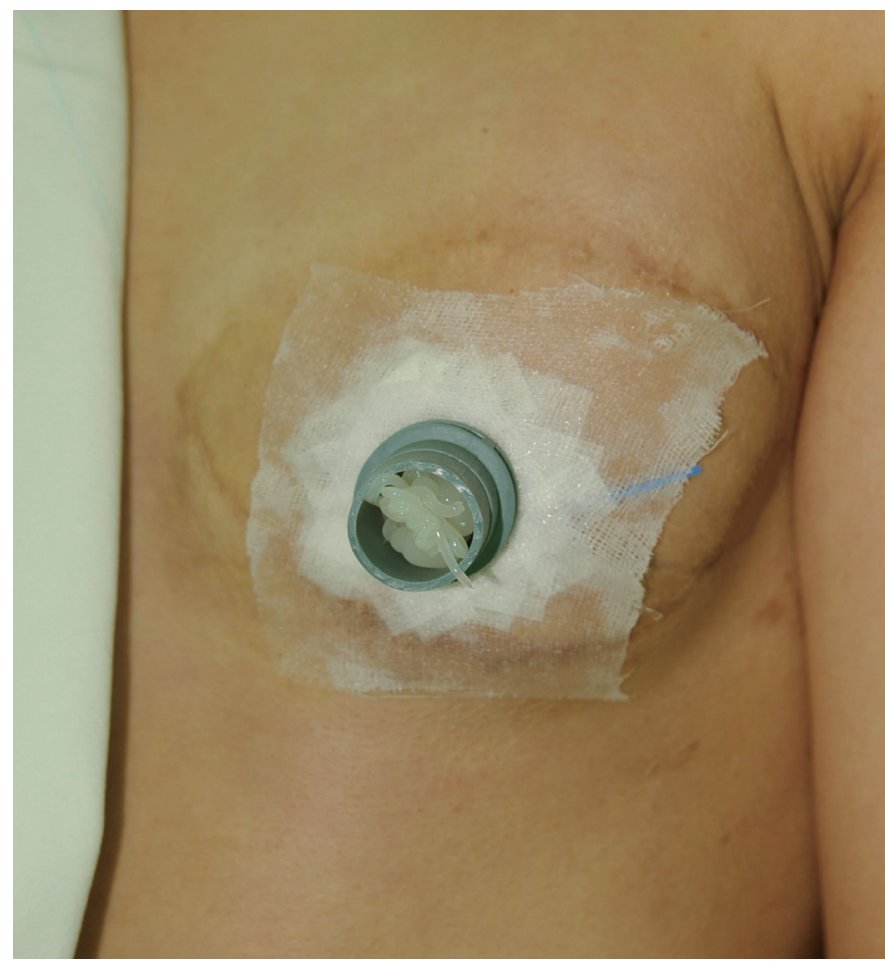

Fig. 4. The dressing using Steri-strip ${ }^{\circledR}$ to avoid a hematoma below the local flap and a breathing bag connecting tube as a protecting device for the reconstructed nipple against pressure.

6). It was the sole means of nipple dressing as a self caring after stitch out. Two months wearing the protective device was advised. 


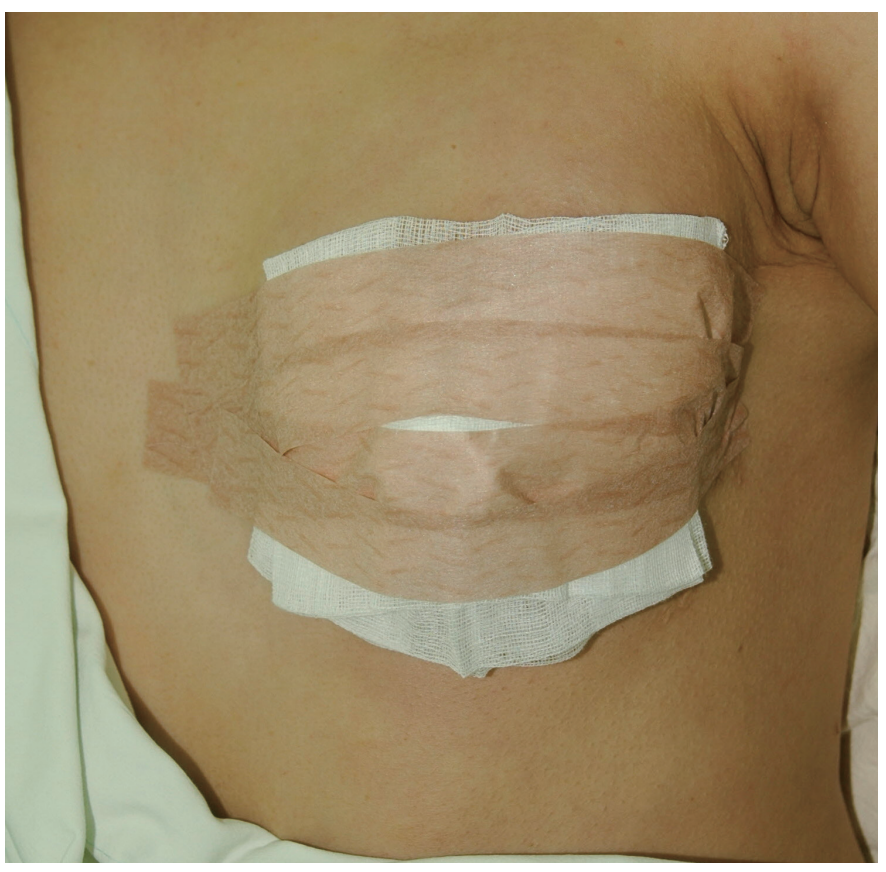

Fig. 5. Image of the nipple reconstruction dressing completed.

\section{Results}

Two patients had worn the breathing bag connecting tube as a nipple protective device for two months with the best compliance.

Owing to the soft composition of the tube material, surgeon's easy cutting and trimming of it at appropriate heights was possible, and patient's long-term compliance could be also possible through safe and easy washing if needed. It also has an advantage of the cost factor, because the connecting tube is usually disposed after single use of anesthesia.

\section{DISCUSSION}

The nipple has a dense connective tissue layer surrounding lactiferous ducts. This dense layer maintains nipple projection [1]. Although diverse methods of nipple reconstruction have been being applied, in principle, the reconstructed nipple cannot be identical to the normal human nipples. Since the local flap coverage is a soft adipose tissue, the reconstructed nipple without rigid connective support is going to be progressively flattened under a physical pressure and tends to be absorbed up to $50 \%$ postoperative loss of nipple projection over the long term [2]. For this reason, it has been a principle to overcorrect the nipple height and to avoid the compressive dressings [1]. In addition, a newly reconstructed nipple is vulnerable due to the flap nature. Necrosis or abrasion may result in contamination and a failed flap [3]. Therefore, a protective guard for reconstructed nipple is necessary.

Different post-surgical efforts to find a physical support against pressure on the reconstructed nipple are reported in the literature

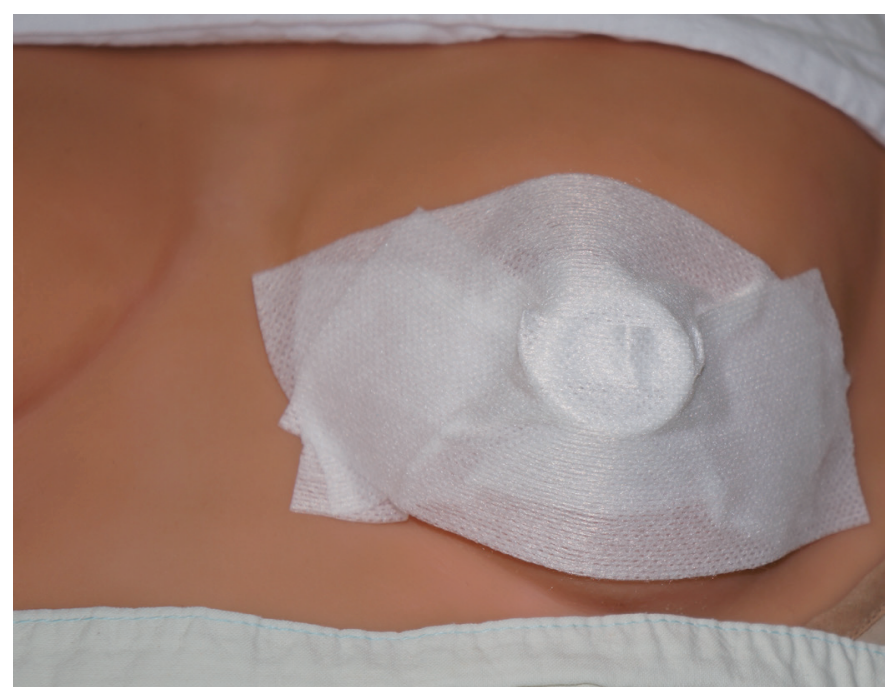

Fig. 6. The breathing bag connecting tube can be simply affixed with adhesive tape (dummy simulation).

such as a nipple splint, a nipple guard, and stent dressing [4-6]. These are innovative usage of a syringe with the Silastic sheet [7], an eye-shield [8], and a silicone nipple shield for an ulcerated nipple during lactation $[1,3]$. To my best knowledge, the 50-cc syringe is the most frequently selected item to protect the reconstructed nipple today. However, it is not easy for a surgeon to cut and trim the syringe. Its sharp cut margin has been also uncomfortable or unsafe for the patient.

Therefore, the authors propose the use of a breathing bag connecting tube as protective device in nipple reconstruction. Owing to its composition of soft material, this lends to easy cutting and trimming at appropriate heights. And the patient's long-term compliance can be possible through safe and easy washing if needed. It also has an advantage of the cost factor, because the connecting tube is usually disposed after single use of anesthesia.

While there is not any consensus on the wearing time of protection device, the authors had two patients wore it for two months with the best compliance. This wearing time has come from Salgarello et al. who did not experience excessive flattening of the new nipple during a 12 month follow-up period [1].

We strongly recommend the use of a breathing bag connecting tube as protective device in nipple reconstruction.

\section{AKNOWLEDGEMENT}

This research was supported by the 2013 scientific promotion program funded by Jeju National University.

\section{REFERENCES}

1. Salgarello M, Cervelli D, Barone-Adesi L. The use of a silicone 
nipple shield as protective device in nipple reconstruction. J Plast Reconstr Aesthet Surg 2008;61:1396-8.

2. Banducci DR, Le TK, Hughes KC: Long-term follow-up of a modified Anton-Hartrampf nipple reconstruction. Ann Plast Surg 1999;43:467-9.

3. Weissman O, Tessone A, Liran A, et al. Silicone nipple shields: an innovative postoperative dressing technique after nipple reconstruction. Aesthetic Plast Surg 2010;34:48-51.

4. Choudhary S, Adams T. The "syringe" nipple splint. Plast Reconstr Surg 2003;112:1182.

5. Spear SL, Beckenstein MS. The nipple guard: an alternative cov- ering for nipple-areola reconstrctions with or without skin grafts. Plast. Reconstr. Surg 1997;100:1509-12.

6. Papay FA, Lucas A, Hutton D. A simple postoperative stent dressing after nipple-areola reconstruction. Plast Reconstr Surg 1997; 99:1787-8.

7. Hyman JB, Newman MI, Gayle LB. Composite syringe dressing after nipple-areola reconstruction. Plast Reconstr Surg 2005;116: 340.

8. Sircar T, Chouhan A, Johri A. Cartella eye-shield as a dressing after nipple reconstruction-a technical innovation. Ann R Coll Surg Engl 2010;92:439. 